\title{
PEMANFAATAN MESIN PENGUPAS KULIT LUAR MELINJO UNTUK MENINGKATKAN PRODUKTIVITAS HOME INDUSTRI DI DESA GUPOLO KECAMATAN BABADAN KABUPATEN PONOROGO
}

\author{
Wawan Trisnadi Putra ${ }^{1)}$, Kuntang Winangun ${ }^{2)}$, M. Malyadi ${ }^{3)}$, Nanang Suffiadi ${ }^{4)}$, Yoga \\ Arob Wicaksono ${ }^{5)}$ \\ 1)2) 3) 4) 5) Program Studi Teknik Mesin, Universitas Muhammadiyah \\ Ponorogo Jl. Budi Utomo No. 10 Ponorogo
}

\begin{abstract}
Abstrak
Tujuan utama dilakukan kegiatan Program Kemitraan Masyarakat (PKM) ini adalah membuat alat pengupas kulit luar melinjo untuk meningkatkan produktivitas home industry di Ds. Polorejo, Kec. Babadan, Ponorogo. Permasalahan kondisi mitra saat ini mengalami peningkatan pemesanan emping melinjo, saat mengalami peningkatan pemesanan dan produksi pengupasan kulit luar melinjo masih manual akan menghambat produktivitas mitra. Permasalahan kedua mitra adalah kurangnya pengetahuan teknologi untuk mempermudah dan mempercepat produktivitas pengupasan kulit luar melinjo. Kegiatan ini sepenuhnya didanai Universitas Muhammadiyah Ponorogo melalui anggaran tridharma masing-masing dosen. Hal ini dilakukan agar mitra lebih efektif dan efisien dalam memproduksi olahan emping melinjo, sehingga meningkatkan kesejahteraan masyarakat. Selain bantuan teknologi, juga memberi pendampingan penggunaan alat kepada masyarakat mitra agar mampu menggunakan alat tersebut. Target kegiatan Program Kemitraan Masyarakat (PKM) ini adalah pembuatan alat pengupas kulit luar melinjo, dan publikasi jurnal pengabdian kepada masyarakat. Metode pendekatan yang digunakan dalam kegiatan Program Kemitraan Masyarakat (PKM) ini adalah pendidikan dan pelatihan, pendampingan, evaluasi. Teknik pelaksanaan kegiatan dilakukan dengan cara memberikan motivasi usaha, pembimbingan manajemen usaha, pelatihan penggunaan alat pengupas kulit luar melinjo. Hasil dari pengabdian ini adalah penerapan teknologi alat pengupas kulit luar melinjo kepada mitra. Mitra setelah diberikan pelatihan dan pendampingan dapat menggunakan alat dengan baik. Sehingga dapat meningkatkan produktivitas mitra yang awalnya menggunakan teknologi konvensional, kemudian menggunakan alat yang lebih maksimal untuk produksi.
\end{abstract}

Kata kunci: melinjo, alat pengupas kulit luar melinjo

Email: kuntang@umpo.ac.id 


\section{PENDAHULUAN}

Pada Desa Gupolo merupakan salah satu desa yang terletak di Kecamatan Babadan, Kabupaten Ponorogo. Bagian utara berbatasan dengan Desa Polorejo dan Japan, selatan berbatasan dengan Desa Keniten dan Desa Ngunut, bagian timur berbatasan dengan Desa Keniten, Japan, Lembah, dan barat berbatasan langsung dengan Desa Polorejo dan Desa Ngunut. Luas Desa ini ialah 126,62 Ha dan memiliki iklim tropis.

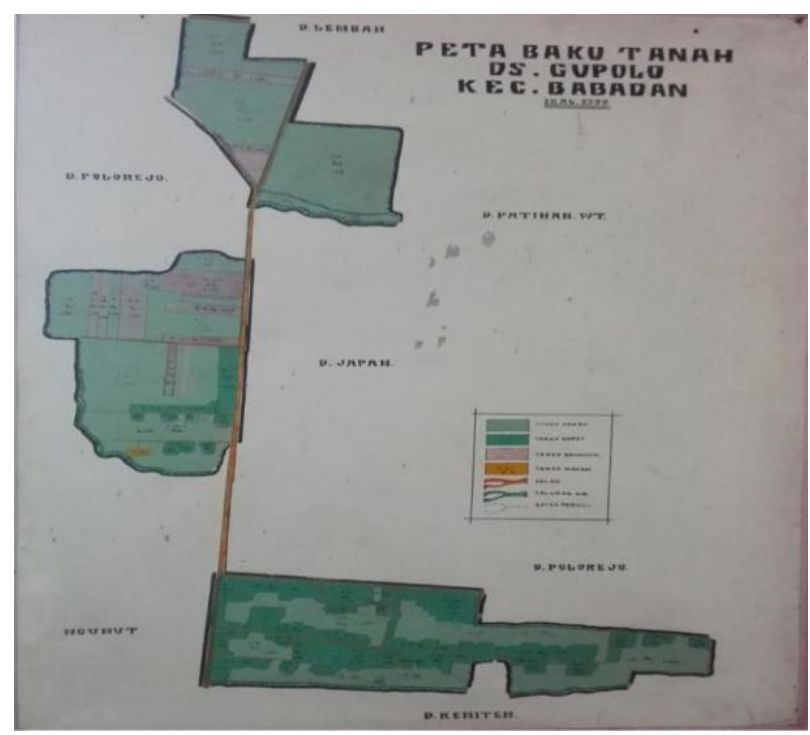

Gambar 1. Denah Peta Desa Gupolo

Tanaman melinjo umumnya mengalami dua kali atau tiga kali masa panen per tahun. Di Desa Gupolo sangat cocok ditanami melinjo karena melinjo menjadi produk unggulan. Pemetikan buah melinjo yang akan dijadikan sebagai bahan baku emping, maka pemetikan buah melinjo yang terbaik adalah bila buah tersebut telah tua, ditandai dengan warna merah muda atau merah tua. Pada umumnya ukuran melinjo berkisar $15 \mathrm{~mm}$, jika belum di kupas. Dan ukuran melinjo ketika sudah dikupas berkisar $11 \mathrm{~mm}$.

Bahan baku yang diterima dari konsumen ke produsen sejumlah $50 \mathrm{~kg} / \mathrm{hari}$ dalam bentuk melinjo yang belum di kupas. Perbandingan melinjo yang belum di kupas $2 \mathrm{~kg}$ menjadi $1 \mathrm{~kg}$ melinjo sudah di kupas. pada tempat produksi emping melinjo mempunyai pekerja 5 orang, setiap orangnya dapat mengupas $10 \mathrm{~kg} / \mathrm{hari}$. Jika di Desa Gupolo perpanen mendapatkan 20 ton, dengan pekerja sejumlah 5 orang untuk mengupas kulit melinjo maka membutuhkan waktu yang sangat lama. Sedangkan untuk produk jadi dari olahan biji melinjo, dalam sehari produsen dapat 
memproduksi $5 \mathrm{~kg}$ emping. Untuk menghasilkan $1 \mathrm{~kg}$ emping maka dibutuhkan bahan baku sebanyak $5 \mathrm{~kg}$ biji melinjo yang sudah terkupas.

Pembuatan produk tersebut membutuhkan waktu yang lama, yaitu 1 jam hanya dapat menghasilkan 0,83 $\mathrm{kg}$ emping. Jadi dalam satu hari produsen mengasilkan $5 \mathrm{~kg}$ emping. Hasil tersebut dikerjakan oleh 5 orang pekerja dengan rentang waktu 6 jam/hari. Ongkos kerja mengupas kulit luar melinjo yang di peroleh setiap orangnya dihitung perkilo, yaitu sejumlah Rp 1000,00. Maka, jika satu orang dapat mengupas $10 \mathrm{~kg}$ melinjo, ongkos kerja yang di dapat selama satu hari sejumlah Rp 10.000,00. Harga 1 kg emping adalah Rp 60.000,00, sedangkan harga $1 \mathrm{~kg}$ melinjo yang sudah di kupas adalah Rp 10.000,00, untuk melinjo yang belum dikupas adalah Rp 2000,00/kg. Produk jadi atau emping yang dihasilkan dari proses produksi tersebut dapat bertahan selama 1 tahun, jika pengeringan dilakukan maksimal selama 2-3 hari dan di bungkus rapat lalu di tempatkan di tempat yang tidak lembab dan jauhkan dari jangkauan air.

Berdasarkan analisis situasi yang ada dilapangan, muncul permasalahan-permasalahan antara lain:

1. Masyarakat Desa Gupolo Kecamatan Babadan Kabupaten Ponorogo yang sebagian besar bermata pencaharian sebagai petani padi serta buruh tani, saat tidak musim panen maka tidak mempunyai penghasilan tambahan untuk memenuhi kebutuhan sehari - hari.

2. Masyarakat Desa Gupolo Kecamatan Babadan Kabupaten Ponorogo banyak yang memiliki tanaman melinjo di sekitar pekarangan rumah, sehingga perlu dimanfaatkan sebaik mungkin untuk dijadikan produk unggulan desa.

3. Masyarakat Desa Gupolo Kecamatan Babadan Kabupaten Ponorogo belum mengetahui teknologi yang tepat untuk meningkatkan produktivitas pengupasan kulit luar melinjo.

\section{MATERI DAN METODE PELAKSANAAN}

Kerangka pemecahan masalah ini dilakukan untuk mempermudah dalam menyelesaikan permasalahan mitra. Adapun kerangka pemecahan masalah mitra dapat digambarkan sebagai berikut: 


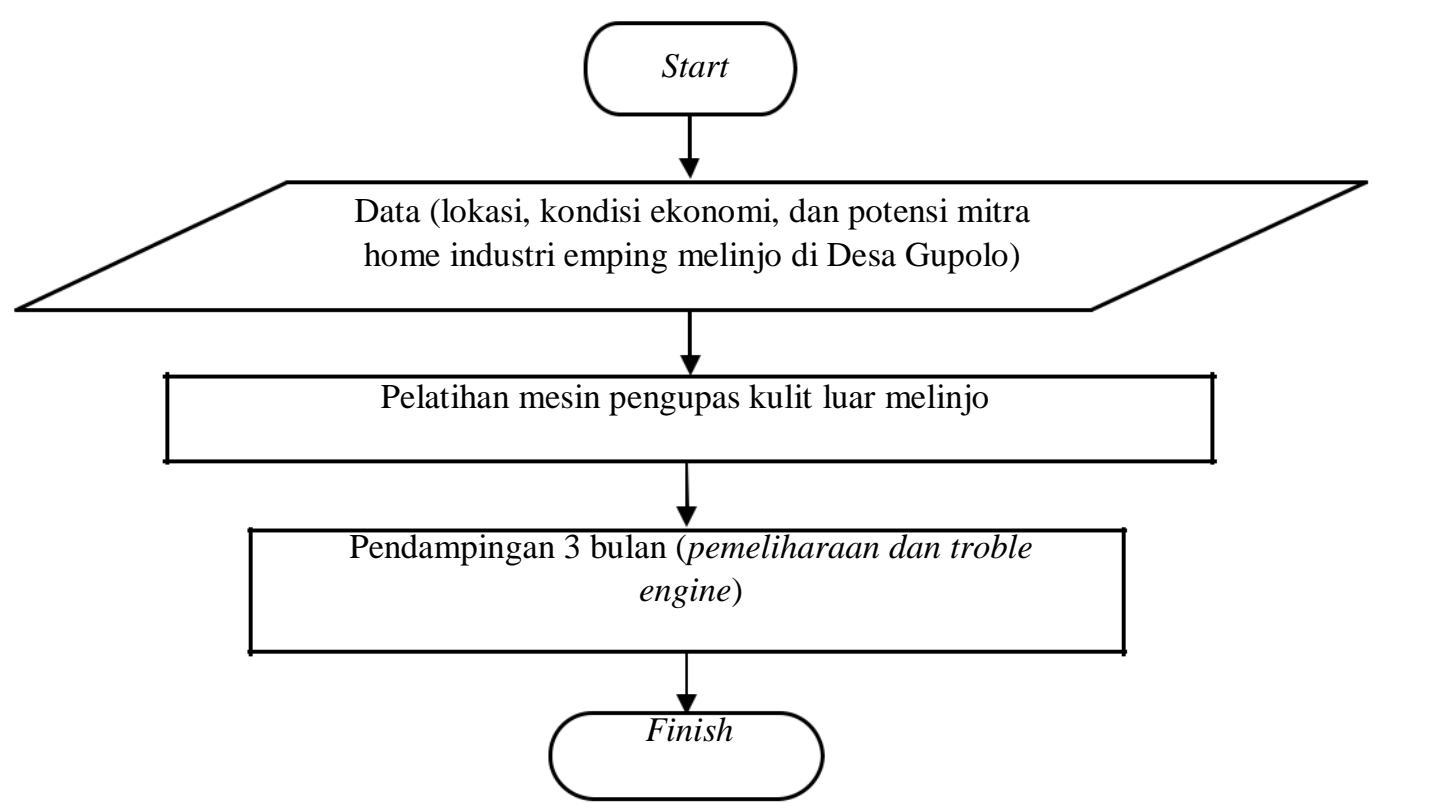

1. Data lokasi mitra. Data lokasi mitra di desa gupolo perlu dilakukan untuk mengetahui kondisi perekonomian di lokasi mitra. Kebanyakan bermata pencaharian sebagai petani, potensi di lokasi mitra banyak terdapat pohon melinjo, ada home industry pembuatan emping melinjo. Belum adanya sentuhan teknologi pada home industry tersebut. Pemesanan semakin meningkat dan mitra tidak mampu karena produksi pengupasan kulit luar melinjo masih manual. Sehingga perlu dibuatkan alat untuk memperepat produksi emping melinjo. Langkah yang perlu pengabdi lakukan adalah membuatkan alat pengupas kulit luar melinjo.

2. Setelah alat sudah jadi dan dilakukan uji kelayakan alat sudah berhasil dengan baik, maka alat siap untuk diserahkan kepada mitra dan dilakukan pelatihan penggunaan alat agar mitra mampu menggunakan akat dengan baik.

3. Proses selanjutnya adalah pendampingan kepada mitra perlu dilakukan agar pengabdi tetap dapat memantau kendala yang dihadapi mitra setelah menggunakan alat pengupas kulit luar melinjo.

Mitra merasa terbantu dengan adanya program pengabdian kepada masyarakat yang diselenggarakan Universitas Muhammadiyah Ponorogo ini. Langkah realisasi untuk memecahkan permasalahan mitra sebagai berikut: 
a. langkah pertama pengabdi membuatkan desain alat pengupas kulit luar melinjo, setelah desain sudah jadi dilakukan pengerjaan alat sampai selesai. Alat sudah selesai dikerjakan maka dilakukan ujicoba alat, saat ujicoba alat pertama belum maksimal dalam pengupasan. Masih ada banyak melinjo yang belum terkelupas, sehingga perlu penyempurnaan alat hingga diujicoba hasilnya semakin baik. Setelah ujicoba selesai dan alat dinyatakan layak untuk digunakan maka dilakukan penyerahan alat kepada mitra.

b. langkah kedua adalah penyerahan dan pelatihan alat pengupas kulit luar melinjo kepada mitra.

2. langkah ketiga adalah pendampingan dan monitoring mitra.

Khalayak sasaran dalam kegiatan ini adalah masyarakat pada Desa Gupolo Kecamatan Babadan Kabupaten Ponorogo yang diharapkan dapat memanfaatkan buah melinjo untuk diolah menjadi bahan emping. Adapun prosedur kerja yang dilaksanakan untuk mengatasi permasalahan di Desa Gupolo Kecamatan Babadan Kabupaten Ponorogo adalah sebagai berikut:

1. Survey

Kegiatan ini dilaksanakan sebelum pelaksanaan pengabdian. Ini bertujuan untuk mengetahui permasalahan yang ada di mitra, mengetahui apa saja yang diperlukan mitra, dan mengetahui apa saja yang menjadi potensi mitra untuk dijadikan pengabdian masyarakat. Dari hasil survey tersebut dapat didefinisikan mitra mengalami peningkatan pemesanan emping melinjo, pengupasan kulit luar melinjo masih manual sehingga menghambat produktivitas mitra. Kebutuhan yang diperlukan oleh warga yaitu mesin pengupas kulit luar melinjo.

2. Pembuatan alat

Desain alat pengupas kulit luar melinjo dibuat dulu, kemudian baru dilakukan pengerjaan pembuatan alat pengupas kulit luar melinjo. Setelah alat sudah jadi kemudian dilakukan ujicoba kelayakan alat dan berjalan dengan baik. 
3. Pelatihan

Kegiatan praktek yang akan dilakukan oleh warga adalah pengoperasian mesin pengupas kulit luar melinjo, pemeliharaan mesin saat selesai melakukan pengoperasian, pendampingan saat terjadi masalah pada mesin, yang dibimbing oleh tim pengabdi.

Kegiatan monitoring dan evaluasi ini dilaksanakan untuk mengetahui kemampuan mitra dalam menggunakan alat dan untuk mengetahui kendala yang dihadapi mitra saat menggunakan alat:

Tabel 1. Evaluasi kegiatan

No Pendampingan Evaluasi kegiatan

Penyerahan alat pengupas kulit luar melinjo. Setelah dilakukan

Pendampingan 1: $\quad$ ujicoba alat oleh peneliti dan dinyatakan layak untuk digunakan

1. Penyerahan alat maka alat siap untuk diserahkan kepada mitra.

Setelah alat diserahkan kepada mitra dan dilakukan pelatihan penggunaan alat. Kemudian dilakukan monitoring pertama yaitu

Pendampingan 2: mitra dapat menggunakan alat dengan baik, dan mitra merasa

2. peggunaan alat terbantu dengan adanya alat pengupas kulit luar melinjo.

Tahap akhir adalah pemeliharaan alat yang didampingi oleh tim pengabdi. Setelah alat digunakan untuk berproduksi selama tiga bulan, ada beberapa komponen mesin yang perlu dilakukan perawatan seperti bearing perlu diberi pelumasan, mesin perlu di

Pendampingan 3: tune-up, dan beberapa komponen perlu dibersihkan. Mitra

3. Pemeliharaan alat Bersama pengabdi melakukan secara Bersama-sama.

Sumber: Data diolah, 2019

\section{HASIL DAN PEMBAHASAN}

Observasi dan wawancara kegiatan PKM dilakukan pada kelompok usaha home industry bernama sido mukti yang dipimpin oleh Ibu Munawar Cholil di Desa Polorejo, Kec. Babadan, Ponorogo. Tujuan dari observasi dan wawancara adalah untuk menggali informasi secara detail 
mengenai proses pengupasan kulit luar melinjo serta permasalahan yang dihadapi mitra ketika proses produksi. Proses observasi dan wawancara ditunjukkan pada Gambar 3.
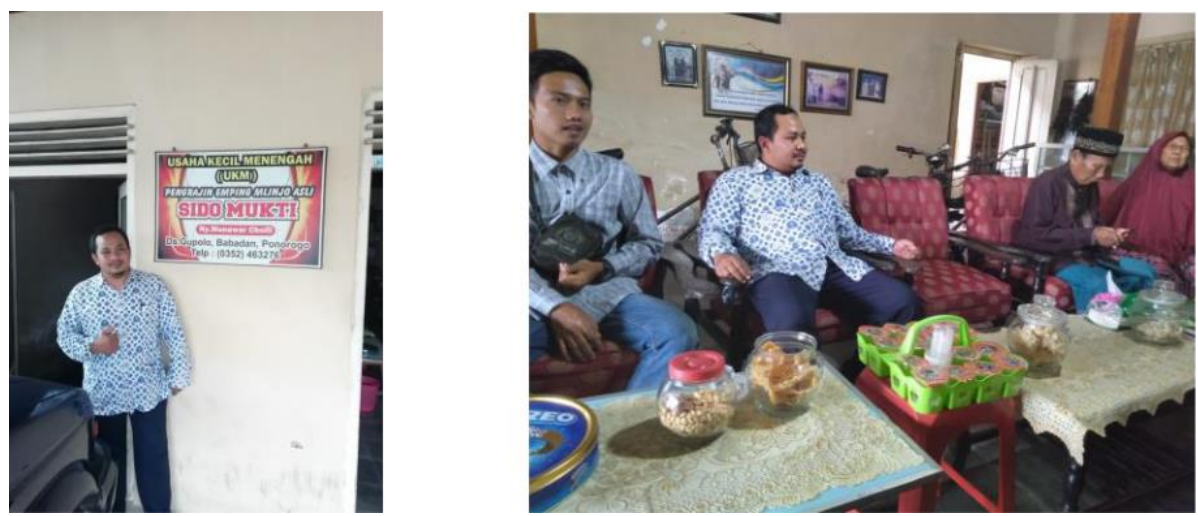

Gambar 3. Observasi dan wawancara pada kelompok usaha sido mukti

Hasilnya menunjukkan bahwa beberapa peralatan pengupasan kulit luar melinjo masih bersifat konvensioal. Ini antara lain proses mengupas masih menggunakan pisau dengan satu per satu melinjo, proses mengupas kulit dalam melinjo masih menggunakan di tumbuk satu per satu. Oleh karena itu, sasaran program PKM yang dituju adalah mengganti proses pengupasan kulit luar melinjo menggunakan pisau menjadi menggunakan mesin yang diputar dengan motor listrik.

Observasi dan wawancara selajutnya adalah untuk menentukan desain alat pengupas kulit luar melinjo yang tepat. Diskusi ini juga mencakup alat dan bahan yang dibutuhkan dalam pembuatan alat pengupas kulit luar melinjo. Tim kembali melakukan kunjungan setelah mendapatkan desain alat yang tepat. Hal ini dilakukan untuk memastikan kemampuan alat ketika melakukan proses pengupasan sehingga sesuai dengan kondisi saat melakukan proses produksi.

Alat yang akan dibuat adalah pengupas kulit luar melinjo:

Proses fabrikasi pengupas kulit luar melinjo dituliskan sebagai berikut.

a. Pembelian alat dan bahan meliputiplat besi, motor listrik dan pahat.

b. Penentuan dimensi pengupas kulit luar melinjo sesuai dengan mitra.

c. Fabrikasi pengupas kulit luar melinjo berdasarkan desain kebutuhan mitra. 

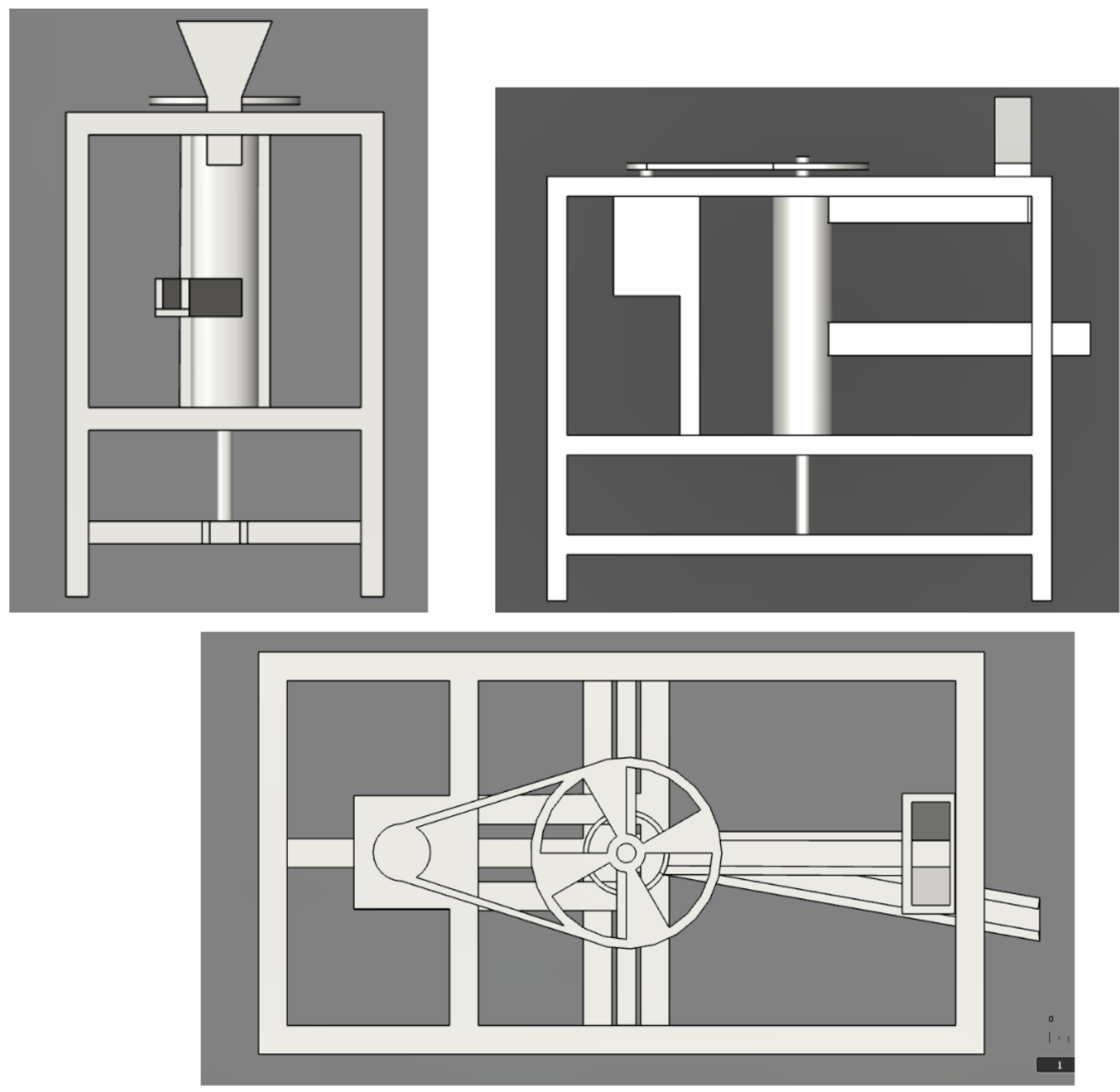

Hasil kegiatan pengabdian masyarakat secara garis besar mencakup beberapa komponen sebagai berikut:

1. Keberhasilan kegunaan alat secara mandiri.

2. Kesesuaian fungsi alat seperti yang diinginkan mitra.

3. Pendampingan secara berkala kepada mitra untuk penggunaan alat.

4. Kemampuan peserta dalam penguasaan materi. 


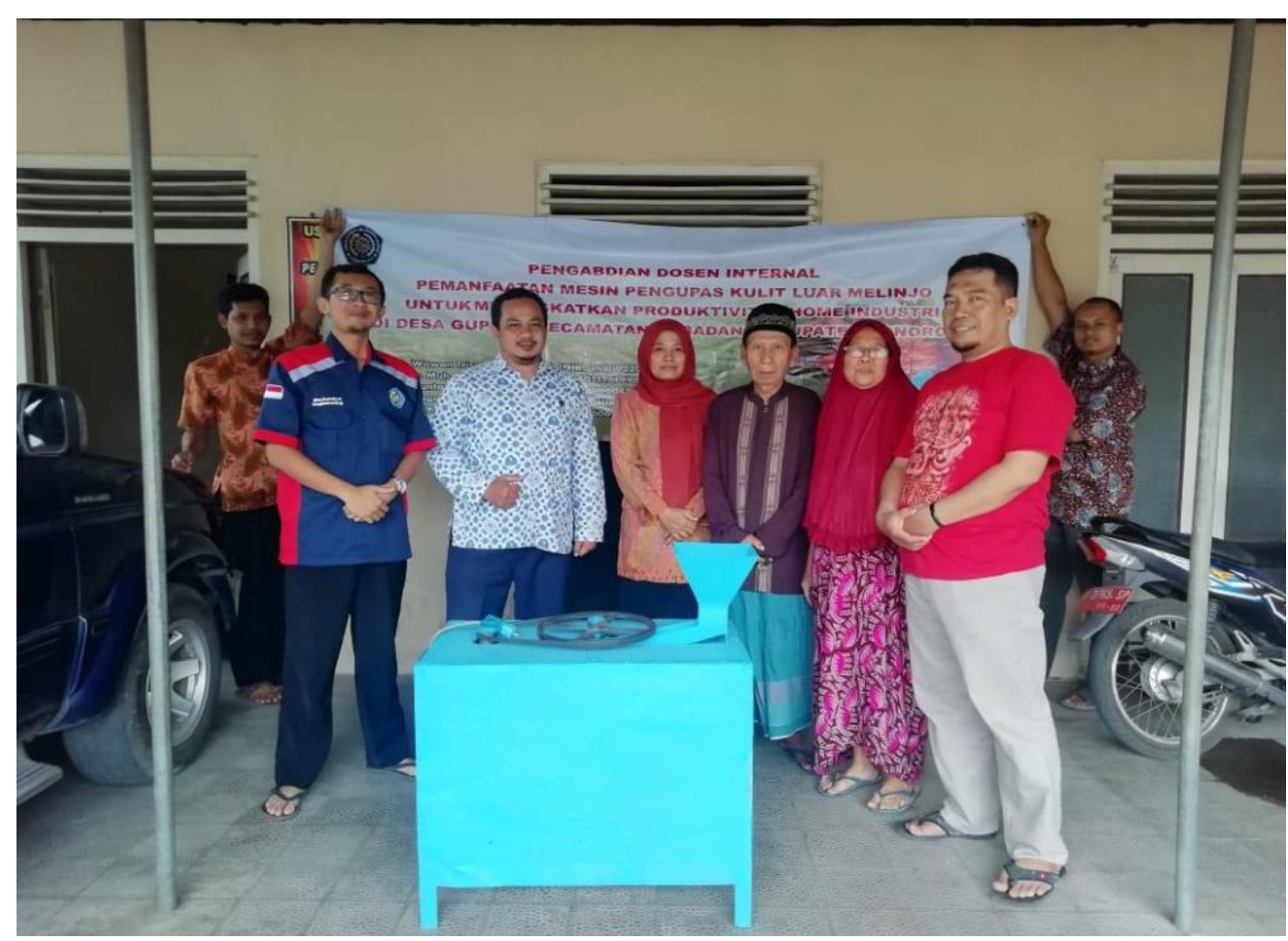

Gambar 4. Penyerahan alat kepada mitra

\section{KESIMPULAN DAN SARAN}

Pemberdayaan masyarakat ini dilakukan pada tahapan pemberian alat pengupas kulit luar melinjo untuk meningkatkan produktivitas mitra di Ds. Gupolo, Kec. Babadan, Kab. Ponorogo. Dalam kegiatan ini mitra sangat antusias, hal ini dikarenakan mereka mitra sangat membutuhkan alat untuk membantu produktivitas supaya lebih efisien waktu dan tenaga.

Kegiatan ini sangat bermanfaat bagi mitra, masyarakat, mahasiswa maupun dosen pelaksana kegiatan Ipteks bagi Masyarakat. Bagi masyarakat kegiatan seperti ini merupakan wujud nyata dunia pendidikan untuk melakukan proses interaksi dengan masyarakat dalam kegiatan nyata dan bermanfaat secara langsung, bagi mahasiswa kegiatan ini merupakan wujud implementasi ilmu yang mereka dapatkan ketika kuliah sehingga dapat mengetahui secara langsung keperluan masyarakat di suatu daerah, sedangkan bagi pengabdi kegiatan ini sangat berguna dalam meningkatkan suatu wujud Tri Dharma Perguruan Tinggi, salah satunya yaitu pengabdian kepada masyarakat.

\section{UCAPAN TERIMAKASIH}

Ucapan terimakasih kami sampaikan kepada Universitas Muhammadiyah Ponorogo yang telah memberi kesempatan dan mendanai sepenuhnya kepada dosen untuk melakukan pengabdian kepada masyarakat sehingga dapat mengaplikasikan ilmunya. 


\section{DAFTAR PUSTAKA}

[1] Afwan Zaini, Muhammad. (2015). Perencanaan Mesin Rangka Mesin Pengupas Biji Kopi Untuk Meningkatkan Kekuatan Penggilasan.. Skripsi Program Studi Teknik Mesin, Fakultas Teknik, Universitas Muhammadiyah Ponorogo.

[2] Direktorat Jenderal Pemberdayaan Masyarakat Dan Desa, Kementrian Dalam Negeri RI. (2017). Format Isian Data Tingkat Perkembangan Desa Dan Kelurahan Tahun 2017. Edisi IV.

[3] Fatoni, Achmat. (2018). Rancangan Alat Pelepas Bearing Hidrolis Multi Fungsi, Skripsi Program Studi Teknik Mesin, Fakultas Teknik, Universitas Muhammadiyah Ponorogo.

[4] Khafidh, Muhammad. (2014). Rancang Bangun Alat Pengelupas Kulit biji Melinjo Untuk Pengembangan Usaha Mikro Kecil Dan Menengah Di Desa Mesoyi Kecamatan Talun Kabupaten Pekalongan. Jurnal Program Studi Teknik Mesin, Fakultas Teknologi Industri, Universitas Islam Indonesia.

[5] Priyo Nugroho, Galih. (2015). Perencanaan Mesin Pengupas Kacang Tanah Dengan Kapasitas 100 kg/jam. Skripsi Program Studi Teknik Mesin, Fakultas Teknik, Universitas Muhammadiyah Ponorogo.

[6] Damar Sancoko, Safarudin Ramdhani, Atiek Prawira (2013). Rancangan Bangun Alat Pengelupas Kulit Luar Melinjo Untuk Meningkatkan Proses Produksi Dan Kualitas Limbah Lanjutan. Program Kreatifitas Mahasiswa, Universitas Dian Nuswantoro, Semarang.

[7] Syawaluddin, Eri Diniardi, M. Alogo. Rancang Ulang Mesin Pengupas Biji Melinjo Berkapasitas 90 $\mathrm{Kg} / \mathrm{Jam}$, Jurnal Jurusan Mesin, Universitas Muhamadiyah Jakarta.

[8] Shodiq, Fajar (2018). Perancangan Mesin Pengupas Kulit Lada Tipe Silinder Tirus Putaran Vertikal. Skripsi Program Studi Teknik Mesin, Fakultas Teknik, Universitas Muhammadiyah Ponorogo. 